\title{
Desenvolvimento: A Nova Ética da Administração Pública $\left(^{*}\right)$
}

\author{
Evangelos John Rizos \\ D.P.A., Consultor da Organização \\ Mundial de Saúde para a Malásia \\ (Tradução de Célia Neves e Dulcy Melgaço)
}

D

ESENVOLVIMENTO nacional é um fenômeno que está surgindo no mundo inteiro e no qual novos niveis de realidade e de percepção estão evoluindo gradualmente. Velhos países enfrentam agora pressões violentas para elevar seus padrões de vida e obter a utilização máxima de seus recursos naturais e humanos. Novos países estão, além disso, aprendendo o significado da independência - a alegria de cuidar dos próprios negócios e a obrigação de tomar decisões e providências em assuntos que os afetam, $\mathrm{O}$ desenvolvimento nacional, porém, não é acidental. Movimentar os processos do progresso moderno, particularmente quando acompanhado de um esfôrço consciente e resoluto, impõe pesados encargos à administração. «Depois do grande movimento de emancipação política» - declarou o Diretor-Geral da UNESCO na abertura da Conferência das Nações Unidas para a Aplicação da Ciência e da Tecnologia em Benefício das Áreas Menos Desenvolvidas - «que ocupou o primeiro plano da história, nos últimos quarenta anos, e que ora se encaminha para o seu término, é claro para tais países que os problemas da organização administrativa, do crescimento econômico e do progresso social se transformarão agora na principal preocupação de seus povos e líderes». (1)

O ponto de vista dominante neste documento é que a qualidade da administração pública num país em desenvolvimento não é uma obsessão quixotesca mas serve de muitas maneiras para elevar ao máximo de sua capacidade as metas do desenvolvimento

(*) Revue Internationale des Sciences Administratives, vol. XXI, 1965,
pp. 279-88.

(1) Science and Technology for Development, Report, Vol. VIII: Plenary Procedings (New York, United Nations, 1963), p. 34. 
ou, ao contrário, para negá-las. Os estudos realizados em diversos países, através do Projeto Mediterrâneo da Organização para a Alimentação e a Agricultura, (2) demonstraram que o desenvolvimento tem sido entravado por deficiências dos quadros administrativos e institucionais.

«Em proporção substancial» - o relatório sôbre o Projeto ressalta - «a estrutura é que determina a capacidade de absorção». Nesse contexto, um dos pressupostos dêste documento é que a administração pública é convocada para montar o cenário que estimulará o padrão de total desenvolvimento do pais, a êle se ajustará com sensatez e proporcionará uma sintese operacional que fará com que os processos de desenvolvimento, uma vez estabelecidos, sejam auto-suficientes. Provàvelmente é êste o problema crucial de todos os governos das nações em desenvolvimento. O nosso objetivo, no entanto, não consiste em descrever a provável ordenação geral das condições e relações administrativas concretas para o desenvolvimento nacional, nem em dar respostas universais a problemas administrativos. Nosso propósito consiste em passar em revista a nova e freqüente esquiva ética da administração pública, em relação a sua receptividade ao desehvolvimento nacional, à luz do cotidiano - um nivel de abstração em que necessidades, dados, metas e práticas assumem um caráter temporal e mutante. Este propósito, porém, implica num intento prático, porquanto, se aprendermos mais coisas sôbre as relações da administração pública com o desenvolvimento nacional, melhor saberemos como the dar maior eficiência.

$\mathrm{Na}$ discussão que se seguirá, três proposições chamarão a nossa atenção: (A) o desenvolvimento nacional está impondo novos encargos à admin stração pública; (B) a vitalidade do desenvolvimento nacional depende do rejuvenescimento da administração pública; e (C) os processos da administração pública não podem ser isolados da corrente principal dos processos de desenvolvimento.

A. Em grau jamais visto, o desenvolvimento nacional está impondo novos encargos à administração pública, exigindo que novos valôres e atitudes permeiem em sua conduta prática.

Quando examinamos o curso provável dos acontecimentos, num país em desenvolvimento, observamos que, até certo grau, a receptividade ao desenvolvimento pode provir do mercado, o qual, por seu próprio sistema de maiores remunerações para a produtividade, cria, para cada participante, uma oportunidade do mais pleno acesso a bens e serviços de sua escolha. Hoje, no entanto, em muitos países em fase inicial de desenvolvimento, uma proporção

(2) FAO Mediterranean Development Project: The Integrated Devclopment of Mediterranean Agricultural and Forestry in Relation to Economic Growth (Rome, FAO, 1959), p. 37. 
relativamente elevada da atividade pró-desenvolvimento é conduzida sob a égide de um govêrno que, segundo se espera, assuma responsabilidade não só pela regulamentação das relações econômicas e pelo aumento de capacidade e oportunidade de investimento no setor privado, mas também proporcione uma infra-estrutura à economia e forneça, às vêzes simultânea e ràpidamente, uma variedade de serviços que outros paises, mais maduros e com experiência de crescimento cumulativo, envolveram gradualmente, sob vários tipos de patrocínios, através de gerações. Falando de modo semelhante, o Professor Riggs observou que o processo de desenvolvimento criou problemas que só podem ser resolvidos através da organização pública e, portanto, através do aumento das atividades governamentais e uma elevação do orçamento. (3) O seguinte trecho do Projeto Mediterrâneo da FAO corrobora esta opinião: «Para que sejam cumpridas as metas estabelecidas nos estudos dos países, o papel do govêrno forçosamente terá de ampliarse além de suas tradicionais funções de assegurar a ordem interna e externa, proteger os direitos civis, prestar serviços públicos e fornecer investimentos gerais em campos como a educação, o transporte e a saúde. Mesmo estas funções tradicionais imporão encargos pesados às autoridades, assim que se envidem vigorosos esforços de desenvolvimento organizado, pois serão necessárias altas qualificações no campo da organização, das finanças e da técnica
especializada. (4) Qualquer que seja a complexidade do cenário contemporâneo,
chegou a hora das decisões cruciais e do contrôle potencial sôbre o curso dos acontecimentos. A velha indagação - será o homem bastante racional para se autogovernar - cedeu lugar a questões mais especificas, referentes às condições sob as quais é possivel tomar decisões e providências para a consecução das várias metas do desenvolvimento nacional. Por exemplo: Como preparar o caminho e testar o campo de trabalho para o avanço? Como captar recursos e aproveitá-los ao máximo? Como liberar e dirigir enerpotencial senvolvimento o crescimento? A necessidade de se abordar o deatenção para nacional de um ponto de vista criador dirige a orientado no sentido dade de um sistema administrativo positivo, prementes se tornam das metas estabelecidas. E, quanto mais tornam os fatôres da ados, intricados, técnicos e extensivos se ção. Parece haver um elementraço pública a levar em consideraseparável do desenvolvimento to particularistico de dinamismo inseparável do desenvolvimento, o qual exige que a administração (3) «Prismatic Society and Financial Administration», 5 Administrative
Science Quarterly (June 1960), p. 15 .

(4) Op. cit., p. 61 . 
pública proceda de conformidade com um padrão de comportamento - experimentar, aplicar, adaptar, seguir, " sidade, ora uma nova oportunidade».

Devemos admitir que poucos poriam em dúvida a desejabilidade de um padrão de administração pública dêsse tipo. Às vêzes, porém, espera-se que a administração pública produza resultados num meio que náo é propício ao desenvolvimento e que muito possivelmente não reflete a expansão ou as responsabilidades atribuidas ao govêrno. Isto não se retere apenas a um país recém-independente mas também a um país que, embora independente, possua um sistema administrativo herdado de um govêrno anterior não interessado no desenvolvimento - ou pelo menos no sentido moderno do têrmo. Pode haver insuficiente liderança politica ou interêsses políticos que se contraponham ao desenvolvimento racional. Conseqüentemente, na ausência de uma tradição politica v gorosa e respeitável, o serviço público, sobretudo quando sustentado por valôres tradicionais, pode formar um dos mais importantes elementos do govêrno. T'odavia, embora possa revelar eficácia na manutenção da ordem e da lei, e até na arrẹcadação de impostos, o govêrno pode ser inadequado para conduzir um programa de desenvolvimento. Seus preceitos e treinamento podem dar ênfase a suas tarefas de guardião da estabilidade e das tradições, mas continuar a refletir os métodos e a lógica de um sistema administrativo dedicado a outros objetivos que não o desenvolvimento. A situação, em todos os países, sem dúvida, não é exatamente a mesma, aqui descrita, mas o importante é que a experiência passada gerou muitos elementos persistentes que, conquanto adequados em outra situação, freqüientes vêzes tendem para tornar ingentes os esforços em prol do desenvolvimento e para transformar a administração pública em vetadora em vez de patrocinadora do desenvolvimento. Enquanto a mentalidade da classe administrativa continuar apegada exclusivamente a velhas práticas administrativas, familiares, e às atitudes personalistas habitualmente dominantes, sempre haverá o perigo de se perder de vista o que há de essencial no desenvolvimento do país. Nesse contexto, oferece particular interêsse um trecho do FAO Africa Survey: «Faz-se mister reexaminar os conceitos atuais sôbre a formação profissional exigida dos administradores africanos. Alguns dêsses conceitos talvez fôssem adequados numa época em que o planejamento para o desenvolvimento econômico e o bem-estar social não figuravam entre os principais encargos do serviço civil. A combinação de qualificações técnicas, intimo conhecimento do ambiente e intima compreensão dos desejos e capacidades das massas exigiriam do moderno administrador africano uma formação especialmente dirigida, diferente daquela formação que se considerava adequada nos dias que as duas qualificações essenciais eram integridade e capacidade administrativa geral. Tais qualidades obviamente continua- 
rão a ser fundamentais, mas deverão ser suplementadas por qualificações mais amplas». (5)

O desenvolvimento nacional apresenta uma situação única, singular. Conseqüentemente, a organização da administração pública não se pode basear na experiência passada. Não pode caminhar para o amanhã com meios e instrumentos de ontem. Eis por que o desenvolvimento nacional exige que novos valôres e atitudes permeiem a conduta prática da administração pública, conforme pronunciamentos partidos de todos os lugares...

... das Nações Unidas: «O desenvolvimento depende em grande parte da qualidade do pessoal administrativo existen te». (6)

... do Mediterrâneo: «Um serviço civil eficiente, dedicado ao desenvolvimento econômico, é indispensável ao bom êxito... Os estudos realizados no país clamam, portanto, por uma reforma da estrutura governamental administrativa e por experiência de novas formas de organização». (7)

... da África: «Há uma crescente compreensão, por todo o Continente, de que os quadros administrativos devem ser radicalmente aperfeiçoados para que os esforços deliberados no sentido de acelerar o progresso econômico e social possam lograr bom exito, para que planos coerentes possam ser elaborados e postos em execuçăo». (8)

... da Ásia e do Extremo-Oriente: «A implementação de um programa de desenvolvimento repousa, em última análise, na máquina administrativa e evidentemente não há mérito em elaborar um programa que não tenha condições de ser implementado». (9)

... da América Latina: «A maior esperança de melhoria reside no interêsse generalizado que surgiu na maioria dos países da América Central e do Sul, pelos problemas do funcionamento do govêrno e na resultante predisposição para introduzir processos novos e modernos». (10) mordial. e novamente das Nações Unidas: «Uma conclusão pri-
me a melhoria da administração é condição sine qua

(5) FAO Africa Survey, Report on the Possibilities of African Rural Development in Relation to Economic and Social Growth (Rome, FAO, 1962),
p. 154.

(6) The United Nations Development Decade, Report of the SecretaryGeneral (New York, United Nations, 1962), p. 106.

(7) Op. cit., p. 61.

(8) Op. cit., p. 123

(9) «Problems and Techniques of Economic Planning and Programming with Special Reference to ECAFE Countries», VI Economic Bulletin for Asia and the Far East (Nov. 1955), p. 60.

(10) Philip M. Glick, The Administration of Technical Assistence: Growth in the Americas (University of Chicago Press, 1957) p. 56. 
non da implementação de programas de desenvolvimento nacional». (11)

B. Embora a aurora se mostre nublada e não seja fácil definit metas, a vitalidade do desenvolvimento nacional depende do rejuvenescimento da administração pública, mesmo na escuridão de conhecimento e prática ainda insuficientes.

O que nos interessa neste ponto é: Como tornar concretas, para fins administrativos nos países em desenvolvimento, generalizações e aspirações de desenvolvimento amplo? Como definir metas de desenvolvimento, com tal clareza, que nos permita adquirir um conhecimento sistemático dos processos e métodos necessários à sua consecução? Evidentemente, a resposta a essas indagações não é suscetivel de cálculos muito rigorosos. Sabemos muitíssimo bem o que pretendemos dizer e no entanto permanecemos curiosamente impotentes na formulação de qualquer detalhe. Se fôsse possivel determinar os fins últimos e reais do desenvolvimento e distinguí-los dos fins intermediários e parciais que na verdade são simples meios ou fases no caminho dos fins últimos, talvez a matéria não fôsse tão difícil. Como é bem sabido, só depois de conhecer com clareza os fins últimos podemos examinar os melhores caminhos e os meios específicos para atingi-los.

O maior problema, aqui, gira em tôrno da questão: como definir o têrmo desenvolvimento nacional com clareza e especificidade. Desenvolvimento nacional não é obra de um artista, destinada a satisfazer seu próprio desejo de auto-expressão. Não significa, tampouco, a formação de uma sociedade perfeita, nem a feitura de uma planta ideal. Tentar-se dar tal concepção ao têrmo desenvolvimento nacional seria torná-lo tão complexo que poucas pessoas, - ninguém, talvez, - estariam capacitadas a possuir o conhecimento factual necessário à compreensão e ava liação do desenvolvimento. Não existe método para determinar os objetivos últimos - talvez só uma espécie de intuição. No entanto, há uma alternativa que merece atenção. Esta interpretação focaliza o país como matriz de seu próprio continuum de desenvolvimento; isto é, o esfôrço de desenvolvimento tem sua origem no país, nêle tem suas raizes, cresce com o país e é renovado e sustentado pelo próprio país. O têrmo desenvolvimento nacional pode então ser empregado para significar a unidade global de processos menores que são entrelaçados por valôres comuns e interligados a um sistema geral de necessidades, cuja origem e cujo fim é o próprio país. Paralelamente ao continuum de desenvolvimento, e em cada fase, há uma política, uma decisão e uma ação adequadas que se conjugam para mais um passo à frente. Há, assim.

(11) United Nations Technical Assistence Programme, A Handbook of Public Administration (New York, United Nations, 1961), p. 1. 
processos para instituições isoladas, como as de saúde e agricultura, ou educação e industrialização, que surgem para fins especificos. Tais processos, compativeis uns com os outros, numa base coerente e coordenada, não remodelam o pais como um todo, mas estabelecem as providências que preparam o caminho para mais um passo à frente. Para quantificar o êxito dêste esfôrço de desenvolvimento, cumpre determinar prioridades e metas, estabelecer certos indices chave, tais como produto nacional bruto e liquido, investimentos governamentais, consumo, emprêgo e desemprêgo, renda per capita.

Surge agora a questão: o que se espera que o desenvolvimento ressalte? Tampouco aqui é possivel generalizar. Ao atacar um programa de desenvolvimento, há várias alternativas para escolher. Um pais pode querer criar um sistema de produção mais eficiente, mediante o estímulo à produtividade; outro, para atenuar os problemas de desemprêgo, pode preferir criar novas oportunidades de emprêgo; um terceiro, desenvolver uma base para a formação de capital, induzindo a população à poupança; um outro, fazer desa parecer o desnivel entre os vários setores da economia, mediante estímulos à elevação dos niveis de vida. (12) Graças à multiplicidade de critérios e porque determinado objetivo pode ser atingido de várias maneiras, não é fácil especificar empiricamente qual o conjunto de condições concretas mais propício ao desenvolvimento. De fato, a escolha do objetivo e a seleção dos meios para sua consecução são dominados por valôres e atitudes prevalecentes em cada país, assim por sua situação econômica e politica, e até por sua política internacional. Observando-se, por exemplo, os países da região da ECAFE (Economic Comission for Asia and Far East), nota-se uma diversidade de escopo e amplitude no esfôrço de desenvolvimento, tal como consubstanciado em seus planos de desenvolvimento. Alguns contêm certas metas agregadas, como - Primeiro Plano Qüinqüenal da Índia, que se refere às taxas de aumento da renda nacional, e o Programa Sexenal do Ceilão, que se refere à taxa de absorção dos desempregados. Outros, como o Primeiro Plano Qüinqüenal do Afganistão, não apresentam metas agregadas por falta de estatísticas sôbre renda nacional e emprêgo. (13)

O desenvolvimento nacional é o resultado global das fôrças em atividade existentes, à época, em qualquer país. Cada pequena contribuição é mais uma peça no crescente mosaico do desen-

(12) Cf. Reuben E. Slensinger, «Basic Problems in Economic Planning for Underdeveloped Countries» in Serial Studies in Social and Economic Scien
ces, Symposia Studies Series No 3 (Washington, National Institute of Social
and Behavioral Science, 1960) and Behavioral Science, 1960), p. 15 .

(13) Cf. «A Decade of Development Planning and Implementation in the ECAFE Region», XII Economic Bulletin for Asia and the Far East (Dec.
1961), pp. 1-2. 
volvimento nacional, embora às vêzes sua conseqüência prática imediata não seja evidente. Essa interligação, quaisquer que sejam as suas diticuldades, é a prática cotidiana da administração pública, só através dela aprendemos como conciliar diretrizes, decisões e ações, como obter conseqüências práticas, como ajustá-las e reajustá-las de modo que possam produzir os efeitos que desejamos. Cabe notar, porém, que quando êste ponto de vista é aplicado a situações rudimentares e incipientes, a administração pública exige maior esfôrço, visão e imaginação, especialmente na procura de uma organização adequada, capaz de proporcionar as tão necessárias pontes para decisões racionais. Se um país sofre crises agudas de escassez, tanto mais sensivel elas tornam as tarefas da administração pública em seu esfôrço de desenvolvimento. Falando em escassez, estamos de fato procurando determinar as exigências que influenciam o funcionamento e a capacidade de solução da administração pública. O problema essencial é saber como desenvolver os recursos disponiveis de organização e encontrar os tipos de relações que reagirão positivamente aos objetivos do desenvolvimento. A administração pública adquire, assim, um nôvo significado prático e assume, pouco a pouco, a forma de um enorme aglomerado de fatos particularísticos e de variáveis qüe têm de ser confrontados uns com os outros. O que torna as tarefas da administração pública mais ingentes, num país em desenvolvimento, não é a urgência de nenhum de seus aspectos, tomado isoladamente, mas o fato de que todos êles têm de se fundir numa sintese trabalhável, capaz de proporcionar, a curto e longo prazo, diretrizes, decisões e ações simultâneas. Estas considerações são importantes sobretudo num país em que a própria falta de uma administração pública eficiente exige um esfôrço pessoal mais deliberadamente dirigido.

C. Os processos da administração pública não podem ser isolados da corrente geral dos processos de desenvolvimento nacional.

Talvez seja um truísmo dizer que os conceitos de desenvolvimento - por mais bem concebidos que sejam, por maiores esperanças que despertem - se revestem de pouca importância, a menos que sejam, primeiro, expressos em planos ou programas bem formulados e realísticos, e depois bem aplicados na prática. Todavia, vale a pena examinar com cuidado êste ponto de vista aparentemente óbvio, porque se trata, aqui, de distinções bem sutis. Estes dois aspectos, a formulação de um plano de desenvolvimento e sua administração, ou, em outras palavras, questões substantivas e processuais, são, com efeito, dificeis de separar. Caminham de mãos dadas e se apóiam um no outro. Por um lado, as questões de desenvolvimento, com todos os seus infinitos detalhes, acham-se tão entrelaçadas com todo o complexo de diretrizes governamen- 
tais e com a administração, que não podem ser consideradas à parte, isoladamente. Por outro lado, os processos da administração pública se fundem de modo particularmente útil com os processos do desenvolvimento nacional, formando, dêste modo, o seu sistema nervoso. Isto é o que freqüentemente se denomina unidade efetiva no desenvolvimento nacional. A propósito, pode-se notar que, no Primeiro Plano Qüinqüenal da India, um dos motivos por que as despesas do plano ficaram aquém das metas foi a inadequação da máquina administrativa existente para tomar a seu cargo o vastíssimo programa incluído no plano de desenvolvimen to. (14)

Na busca das metas de desenvolvimento, o pêso das necessidades de operações práticas torna imperativo que sejam sincronizados os esforços conjuntos de tôda a organização governamental. Isto significa que cada órgão do govêrno terá de desempenhar seu trabalho como parte integrante do esfôrço de desenvolvimento, mas no contexto de seus próprios interêsses, de suas próprias diretrizes. A cada estágio da progressão do desenvolvimento, cada órgão do govêrno terá de tomar a seu cargo novas e crescentes atividades e, em conseqüência, enfrentará inúmeras questões administrativas, novas e cheias de detalhes para as quais terá de descobrir um método para adaptá-las às necessidades específicas a serem atendidas, bem como às realidades políticas, econômicas e sociais. Dêste ponto de vista, pode parecer que a administração pública num pais em desenvolvimento não inclui nada fundamentalmente nôvo; nas palavras da ECAFE, «quando o govêrno funciona eficientemente e os processos de coordenação lhe são naturais, pouca coisa nova, talvez, em matéria de administração específica e geral, terá de ser acrescentada, para o planejamento e execução dos programas de desenvolvimento de cada repartição». (15) Mas nem sempre êste é o caso. Por exemplo, Clair Wilcox, referindo-se às Filipinas, observa que as diretrizes e os programas dos departamentos do govêrno, até 1960 , não tinham relação alguma com os planos de desenvolvimento do país». (16) Quanto ao Plano Octonal de Burma, adotado em 1953. Wilcox declara que «o programa de vários ministérios e órgãos não evoluía como parte integrante do plano. No início, a agricultura foi excluida do âmbito de competência dos planejadores; um outro plano agrícola, separado, foi preparado pelos burmeses.

(14) Op. cit. «Problems and Techniques of Economic Planning and Programming with Special Reference to ECAFE Countries», p. 60.

(15) Ibid, p. 58.

(16) The Planning and Execution of Economic Development in Southeast Asia, Ocasional Papers in International Affairs, N 10 (Cambridge. Mass,
Harvard University Center for International Affairs, 1965), p. 10. 
Elaboraram-se programas independentes, com o auxilio de assessôres das Nações Unidas, para a educação, saúde e habitação. A firma KTA (Knappen Tippetts Abbett Engineering Company) apresentou programas para transportes, indústrias e energia. O resultado foi uma estrutura global de macroeconomia, acompanhada, no setor público, por vários programas não relacionados entre si. A esta altura não existia nada que se parecesse com um plano de desenvolvimento plenamente integrado». (17) Relativamente ao Plano para Duplicar a Renda Nacional (1961 1970), do Japão, observa Shigeto Tsuru que o documento do plano, após enumerar medidas de desenvolvimento, simplesmente acrescenta um curto trecho dizendo que «a fim de atingir êstes objetivos, será necessário que o govêrno se esforce ao máximo no desempenho de suas funções de apoio e aceleramento». (18) A seguir, Shigeto acrescenta que é bem possivel que a omissão de providências específicas tenha sido deliberada, a fim de que os ministros interessados pudessem elaborar propostas concretas, quanto a medidas legislativas e outras providências administrativas acaso necessárias, à medida que a ocasião exigisse.

\section{A FUNÇÃo DE PLANEJAMENTO}

O planejamento, como estratégia para o crescimento, é um aspecto dinâmico e contínuo no processo de desenvolvimento. Mas o planejamento para o desenvolvimento é um fenômeno multilateral e incerto. Não é matéria apenas para o planejador do desenvolvimento, mas uma obra de cooperação. Pode-se dizer que a promessa suprema do planejamento é sua capacidade de conciliar as várias metas de desenvolvimento e realizar aquilo que dará a maior satisfação ao povo.

A experiência tem demonstrado que a articulação de um plano de desenvolvimenı não é empreendimento monolítico; cumpre que os vários componentes do plano sejam absorvidos e assimilados pelos respectivos órgãos governamentais, na consecução de seus objetivos específicos, um aspecto que afeta substancialmente a natureza das relações organizacionais. A propósito, cabe ressaltar que o planejamento faz um corte transversal nos setores convencionais da organização governamental, mas é preciso estabelecer um contato centralizado qualquer, para que se tenham diretrizes claras partidas da autoridade competente em matéria de objetivos, recursos e sua distribuição, instrumentos aceitáveis de diretrizes e implementação, etc. Todavia, o planejamento

(17) Ibid, pp. 19-20.

(18) Citado em «Formal Planning Divorced from Action: Japan», in E. E. Hagen, Ed. Planning Economic Development (Homewood, Ill. Richard D. Irwin 1963) p. 142. 
do desenvolvimento envolve mais ajustamento que imposição de opiniões do órgão central de planejamento. O que importa, aqui, não é tanto decidir em que departamento ou unidade do govêrno êste órgão será localizado, mas estabelecer que êle tenha acesso e relações viáveis com todos os órgãos que atuam no desenvolvimento. São necessárias consultas continuas e esforços de coordenação, não só para evitar incoerências, discrepâncias, como também para evitar que o prestígio de um órgão acabe determinando a formulação e o resultado do plano. Em conseqüência, o problema da coordenação apresenta muitos pontos delicados. Quando existem muitos centros de decisão, é necessário levar em consideração todos os esforços dos componentes inter-relacionados, ao elaborar os processos de planejamento e estabelecer as metas e escalonar as técnicas destinadas a despertar atitudes de cooperação e receptividade. Além disso, é necessário criar um bom sistema para coleta, registro, análise e divulgação de dados sôbre os recursos essenciais do país, sem o que o planejamento do desenvolvimento basear-se-á em fatos fragmentários e imprecisos. Em decorrência da insuficiência de conhecimento, multiplicam-se as probabilidades de se chegar a conclusões erradas, pois, ao planejar, muitas decisões terão de basear-se em previsões a longo prazo.

Clair Wilcox, ao apresentar o caso das Filipinas, observa que, nas primeiras tentativas, a responsabilidade pelo desenvolvimento foi atribuída ao Conselho Econômico Nacional. A composição dêste órgão estatutário não o recomendava para ơ desempenho da função de estabelecer políticas; sua localização na estrutura governamental não o habilitava para tornar efetivas suas determinações; por outro lado, não se achava devidamente equipado para desempenhar a função técnica do planejamento. Esta última foi delegada ao Bureau de Planejamento Nacional. «Houve época» - observa Wilcox - «em que êste Bureau dispunha de pessoal capaz de elaborar bons planos. Mas a qualidade do seu trabalho caiu muito, à medida que se patenteou que os planos, depois de prontos, eram engavetados. Nessa situação, o Bureau de Planejamento Nacional ficou isolado e impotente. Seus planos não resultavam da formulação de um programa pelos departamentos e órgãos do govêrno; eram produto de um exercício realizado no papel, conduzido num vácuo politico. Pareciam isotéricos, inintelegiveis, irrelevantes. O Bureau chegou, assim, a ser considerado apenas como um grupo de estudo. Por falta de influência acabou, com efeito, adormecendo». (19) WolfGang STOLPER, escrevendo sôbre o desenvolvimento da
Nigéria, diz que «um dos principios básicos na elaboração do

(19) Op. Cit., p. 10. 
Plano de Desenvolvimento Nacional era considerar que a função da Unidade de Planejamento Econômico consiste em coordenar e assistir mais do que em impor uma vontade central. Até certo ponto isto era inevitável por causa da organização federativa da Nigéria e de seu profundo senso de autonomia regional. Mas também nós desejávamos despertar o interêsse e utilizar a experiência de pessoas situadas na base da escala, de modo a conquistar a maioria para o processo de desenvolvimento.

Julgamos absurdo, em qualquer hipótese, que um homem sentado na cidade de Lagos ou em qualquer uma das capitais regionais, pretendesse conhecer em profundidade assuntos como o problema agrícola da área do Lago Chad. Em conseqüência, recomendamos uma estrutura de planejamento levantada de baixo para cima e a descentralização do poder de decisão, na execução do plano». (20)

\section{A FUNÇÃO DE ORGANIZAÇÃO}

O desenvolvimento nacional apresenta problemas especiais no tocante ao tipo de organização exigido. Também aqui o tipo da organização dentro da qual se terá de processar o desenvolvimento do país pode não oferecer uma estrutura adequada. A maneira pela qual inúmeras pessoas interessadas nas metas do desenvolvimento vêem seus problemas, cada qual ao seu modo, e assim exercem seu julgamento, a maneira pela qual cooperam e adaptam suas ações à estrutura governamental geral, suscita importantes questões acêrca das formas de organização adaptáveis às metas do desenvolvimento.

Primeiro, cumpre estabelecer uma nítida divisão de competência e adaptar os contrôles organizacionais de modo a ressaltar mais a ação conjugada que os pesos e contrapesos. Pode-se descobrir, por exemplo, que as obras de irrigação estão distribuídas pelos Ministérios da Agricultura, de Obras Públicas e órgãos de desenvolvimento. O levantamento da FAO sôbre a África ressaltava que era necessário melhorar e integrar a estrutura do Ministério da Agricultura. «A aceleração planificada da agricultura, no quadro do desenvolvimento econômico e social geral, requer que vários serviços - conservação do solo, irrigação, pecuária, silvicultura e pesca - atuem como unidade, com base num plano coerente, a longo prazo, ao qual se devem submeter também as emprêsas».

Em seguida, temos o problema de centralização versus descentralização. Nos estudos realizados pela FAO em seu Projeto

1963) pp. 177-178.

American (Set.

(21), Op. cit., p. 153. 
Mediterrâneo, o salto da economia iugoslava a partir de 1953 foi atribuido a certas modificações: «A descentralização da administração pública, a solução de continuidade ocorrida na direção administrativa, a introdução do sistema de autodireção comunal em todos os setores da vida social e a administração das emprêsas pelos trabalhadores - tudo isso teve como efeito a liberação da iniciativa do pessoal-chave, e o estímulo à rápida melhoria da economia que se efetuou com a mobilização dos recursos potenciais, anteriormente sufocados pelo sistema da administração centralizada». (22) O Irã é um outro exemplo. Olsen e Rasmussen, referindo-se ao Segundo Plano Septenal (1955-1961), observam que a dificuldade em dar execução à politica de desenvolvimento econômico no Irã consiste ùnicamente na concentração do govêrno em Teerã. Não existe um sistema de organização para a coorvando em consideração» - observam Olsen e Rasmussen - «que - Irã equivale à França, Espanha, Alemanha e Itália reunidas, e possui um sistema de comunicação muito menos desenvolvido que qualquer dêsses paises, é evidente que uma organização administrativa que concentra tôda a autoridade na Capital tem de ser prejudicial ao bom funcionamento e coordenação da execução do programa, mesmo que fôsse ideal a administração central na Capital. (23)

Os benefícios que a descentralização pode trazer, segundo o estudo feito pelo Programa de Assistência Técnica das- Nações Unidas, são os seguintes: «Antes de tudo, o povo terá melhor compreensão do que o govêrno pretende. Através desta compreeñsão estará mais apto a adotar as novas idéias e práticas, usar os serviços oferecidos, contribuir com seus próprios esforços e recur sos para o programa, dar vitalidade às novas instituições e fazer em suas vidas ajustamentos construtivos, talvez exigidos pelas reformas inicialmente propostas, concorrendo, assim, para que as reformas perdurem... Segundo as atividades de desenvolvimento do goverrno central podem tornar-se mais realísticas mediante a participação local do povo nas decisões de monta. Com isso o conhecimento local, suas necessidades e interêsses terâo melhor partinidade de ser levados em consideração. Finalmente, a e facilidades, deporar aumenta as probabilidades de que os serviços didos. Além depois de estabelecidos, serão mantidos e até expanmunal encoraja, o bom êxito em satisfazer uma necessidade co- experiência

(22) Op. cit., p. 183.

(23) «An Attempt at Planning in a Traditional State: Iran», in E. E.
Hagen, Ed., op. cit., p. 230 . 
adquirida com o estabelecimento e a administração de um serviço comunitário é cumulativa, gerando novas fontes de iniciativa e liderança». (24)

\section{A FUNÇÃO DE PESSOAL}

A disponibilidade de pessoal treinado e competente tem causado grande preocupação. Atua muitas vêzes como freio ao desenvolvimento nacional. Tem-se reconhecido que a escassez de pessoal qualificado, mais do que a escassez de recursos materiais ou financeiros, é, isoladamente, a dificuldade mais significativa para o esfôrço de desenvolvimento. A êste respeito Louis WALINSKY observa que «para melhorar a qualidade, o moral e o desempenho funcional dos empregados seriam necessárias providências em todos os sentidos indicados - a fixação de padrões adequados para admissão, estabilidade, promoção e aposentadoria; padrões de salários adequados; condições físicas satisfatórias de trabalho, inclusive equipamento, supervisão e direção capaz e atenta; e, talvez mais do que tudo, convicção e reconhecimento de que o trabalho a ser feito está de fato contribuindo para o esfôrço de desenvolvimento nacional». (25)

Esta tarefa se tem revelado intricada e talvez tremenda. Não é fácil conseguir que os funcionários transfiram seu devotamento para instituições novas e impessoais, sobretudo em sociedades altamente personalistas, com uma rêde cerrada de laços afetivos.

Não é possivel prestar os múltiplos serviços necessários ao desenvolvimento nacional, desde as fases iniciais dos levantamentos preliminares até o oferecimento de novos serviços e programas, sem o prévio dimensionamento, qualitativo e quantitativo, das necessidades de pessoal. Para preencher os numerosos novos cargos criados, é preciso dispor de dados e estatísticas de pessoal, bem como estimativa do número de empregados necessários, durante um longo período de tempo. O sistema de classificação do pessoal deve levar em conta questões de antigüidade e escala de salários, de modo a equilibrar a procura relativa das várias categorias profissionais e a manter em seus quadros os empregados treinados. No caso do Paquistão, Clair Wilcox atribui o fracasso em recrutar e manter um corpo de técnicos talentosos à recusa de conceder ao pessoal do serviço de agricultura os mesmos salários, promoções e prestígio conquistados por outros serviços. (26)

(24) Descentralization for National and Local Development (New York, United Nations, 1962), p. 7.

(25) The Planning and Execution of Economic Development (New York, McGraw-Hill, 1963), p. 130.

(26) «Pakistan» in E.E. Hagen, Ed. op. cit. pp. 66-67. 
Além disso, cumpre criar um sistema que permita injetar conhecimentos tecnológicos no processo de desenvolvimento. A India é um exemplo interessante. John P. Lewis observa que «a grande dificuldade da Índia, neste campo, tem sido, primeiro, a incapacidade de distinguir claramente outras questões, cuja decisão compete essencialmente a profissionais especialmente treinados, e aquelas que cabem à livre decisão do processo politico burocrático; e, segundo, a incapacidade de formar quadros com os melhores especialistas existentes dentro do govêrno ou não os ter vinculado aos quadros de tal modo a que, quando consultados sôbre problemas especiais de planejamento do desenvolvimento, pudessem ser ouvidos através dos escalões e canais administrativos, que, geralmente, funcionam como amortecedores». (27)

No caso da África, «isto envolve, em primeiro lugar, uma modificação no status relativo de administradores, cientistas e técnicos. Muitos elementos de valor técnico e científico, já de si escassos, estão sendo desperdiçados pela tendência, entre os técnicos bem qualificados, inclusive agrônomos altamente especializados, de preferirem ocupar cargos puramente administrativos, que proporcionam remuneração mais elevada ou maiores oportunidades de promoção. O resultado é que a execução da política e a divulgação de conhecimentos especializados ficam enormemente prejudicados. Dever-se-ia conceder igual remuneração a todos os especialistas de igual nivel, já que há escassez de técnicos e é grande sua procura no mercado, reconhecendo-se assim que os especialistas no campo da técnica, da ciência e da economia têm tanto a oferecer quanto o administrador». (28)

A necessidade de atrair e conservar homens capazes, altamente motivados e qualificados, é ilustrada por Peter Clark em sua descrição do Serviço Civil da Nigéria, que mantém os melhores padrões de eficiência, entre os paises africanos recém-emancipados. "O ritmo da nigerização» - observa - «acelerou-se ràpidamente durante o primeiro ano e meio de independência, provocando uma solução de continuidade no trabalho em curso. Entre os jovens funcionários, duas fôrças opostas causaram tensões cada vez mais acentuadas. Por um lado, a rápida mudança era aceita, pois trazia promoções, embora causasse tensão sôbre métodos, metas, antigüidade e classificação, status e oportunidades de fazer carreira... Por outro lado, uma parcela considerável do serviço civil resistia às reformas e inovações, sobretudo os funcionários mais antigos, ocupantes de cargos estáveis dentro do antigo sistema, mas que agora eram empurrados por funcionários mais jovens, de melhor formação profissional... Os novos servi-
dores civis tinham de competir com uma hierarquia rígida que os

(27) «India», in E.E. Hagen, Ed. ibid., p. 105.

(28) FAO Africa Survey, op. cit. p. 154. 
forçava a rebaixarem o seu padrão de iniciativa, mostrando-se, assim, apenas moderadamente diligentes». (29)

\section{A FUNÇÃO ORÇAMENTÁRIA}

O orçamento anual é um instrumento de importância vital no processo de desenvolvimento. O plano qüinqüenal pode referir-se de maneira bastante especifica ao progresso que se pretende conseguir durante o periodo, assim como às medidas mediante as quais se concretizará, mas a sua realização não se encontra no próprio plano: encontra-se no orçamento anual do govêrno e nas providências de ordem legislativa ou administrativa. Isto significa que qualquer plano de desenvolvimento a longo prazo tem de ser dividido numa série de programas anuais, integrados no processo orçamentário anual. Cabe ressaltar, neste ponto, que o processo orçamentário anual deve rever, ano após ano, o plano de desenvolvimento.

Alguns países incorporaram as várias fases do plano de desenvolvimento ao processo orçamentário; em outros, nada se fêz nesse sentido. Clair Wilcox, por exemplo, relata que, nas Filipinas, a Comissão de Orçamento preparava programas financeiros com prioridades que diferiam das prioridades incluídas no plano de desenvolvimento. (30) No caso da Tailândia, Wilcox relata que «o plano de desenvolvimento, aprovado pelo Gabinete, ao que parece, influencia a ação orçamentária. Na realidade, porém, o Bureau de Orçamento ao proceder ao exame das propostas orçamentárias considera as prioridades anuais contidas no plano como um entrave. Diz-se, outrossim, que o processo de elaboração orçamentária melhorou muito nos últimos anos, em competência e integridade. Mas as funções de planejamento e orçamento não se acham integradas; o orçamento não se subordina ao plano de desenvolvimento. As repartições mais prestigiadas costumam obter as dotações que desejam mesmo quando não incluidas no plano, quer convencendo o Bureau de Orçamento, quer passando por cima de sua autoridade». (31)

Há também necessidade de uma programação anual do desenvolvimento, em decorrência de modificações acaso ocorridas nos custos dos programas ou das receitas dêles provenientes, ou seja, da disponibilidade de recursos. É através de ajustamentos anuais, realizados em conjunto com o orçamento anual, que os planos de desenvolvimento se mantêm em harmonia com a modificação de condições. Além disso, cumpre prever despesas de ma-

(29) «Economic Planning for a Country in Transition: Nigeria» in E. E. Hagen, Ed., op. cit., pp. 264-265.

(30) Op. Cit.

(31) Op. Cit., p. 17. 
nutenção, em si mesmas não desenvolvimentistas, porquanto algumas dessas despesas são indispensáveis para complementar ou operar programas novos, à medida que êstes se completam. Quando se constroem novas escolas, é preciso incluir dotação para pagamento de professôres. Se novas estradas são construidas, devese incluir dotação para sua conservação.

Sem êsse clima administrativo, não há garantia de se atender a um dos requisitos de desenvolvimento: o equilibrio entre metas e programas de expansão, entre despesas e receitas. As práticas orçamentárias tradicionais; que refletem um clima de incompreensão administrativa, constituem um modêlo processual nada recomendável. A conduta diária da administração é capaz de afastá-la, em vez de aproximá-la, das metas do desenvolvimento.

\section{A FUNÇÃO DE DIREÇÃO}

A capacidade para tomar decisões acertadas na conduta diária da administração pública constitui um de seus mais difíceis problemas. À medida que, com o desenvolvimento do país, o exercício do poder de decisão vai-se tornando cada vez mais complicado, mais difícil se torna também o problema de apurar as conseqüências das decisões. Na prática cotidiana da administração pública, há muitas oportunidades que numa atmosfera de insensibilidade ética ensejam decisões administrativas individuais, isoladas, ou interpretações ao acaso, em divergência com as diretrizes e os planos de desenvolvimento geralmente aceitos. Mesmo na melhor das intenções, pode-se tomar decisões «em cima da perna», sem qualquer informação básica e em desacôrdo com as recomendações resultantes da análise dos problemas. Ou então, pode prevalecer a atitude contrária, de suspender qualquer decisão, e, em conseqüência, qualquer ação. Assim, tanto a tomada de decisões não fundamentadas, como a suspensão da decisão, quando ignoram as opções feitas na politica de desenvolvimento, deixam de ser eficazes, em têrmos do momentum do desenvolvimento. E em conseqüência surgem inúmeras diretrizes e práticas administrativas incompativeis e até contraditórias com o esfôrço de desenvolvimento. Do mesmo modo, temos a fixação de metas quanti-
tativas e prazo para a consecução das várias fases do desenvolvimento nacional. Isso conduz ao que talvez seja a caracteristica precípua da administração pública, no desenvolvimento nacional, quando comparada com sua prática tradicional, isto é, sua dependência de decisões e providências no devido tempo. Os processos num ponto provocará um atraso de efeito cumulativo num outro ponto qualquer, frustrando ou perturbando o conjunto das atividades. Apesar disso, parece, às vêzes, quase impossivel injetar uma psicologia de eficiência, uma psicologia de observância de um 
calendário de trabalho, enquanto, como diriam os economistas, o transcorrer do tempo humano não fôr considerado valioso e escasso.

Podemos concluir esta seção tratando da questão do arbítrio. Regulamentos e normas administrativas já consagradas, que se aplicam igualmente a tôdas as situações e que seguem o fenômeno normal do precedente, podem impedir a solução do caso excepcional. E é exatamente o caso excepcional o único que os funcionários da administração pública provàvelmente encontrarão no curso do desenvolvimento nacional. Numa situação única, a decisão a tomar, a providência a tomar, tem forçosamente de ser única e individualizada. Uma coisa é seguir o precedente firmado, a êle aderir, e neste sentido ser impessoal. Outra coisa, porém, é tratar o caso excepcional de maneira passiva, como se fôsse uma questão secundária. Isto não quer dizer que a opção deva basear-se num comportamento arbitrário; significa que se deve adotar um outro critério, que não o precedente, capaz de ressaltar valôres e necessidades características do desenvolvimento nacional. A impersonalidade e a rigidez devem ser temperadas pelo mérito do caso ocorrente e a maneira como êle se enquadra no esfôrço de desenvolvimento. $\mathrm{O}$ único critério válido ao tomar uma decisão administrativa é saber se ela contribui ou não para o desenvolvimento. Aplicada ao caso único, excepcional, a decisão gera um tipo de dilema que cada dia se apresenta com maior freqüência aos que trabalham na administração pública. Pode-se até dizer que, no desenvolvimento nacional, a imparcialidade oficial, divorciada das metas do desenvolvimento, é um mito.

Apesar de a magnitude e a complexidade da administração pública se afirmarem quase esmagadoras, no próximo desenvolvimento nacional, elas são vistas na devida perspectiva.

Embora ainda haja muito que aprender sôbre o jôgo de fôrças no desenvolvimento nacional e seus processos, as lições da experiência recente têm revelado que muitas correntes estão convergindo para a administração pública, a fim de lhe conferir uma significação sem precedentes. Com efeito, no momento que se decidiu enfrentar o desenvolvimento, é inevitável que as opções e os meios instrumentais se tornem inseparáveis dos problemas mais gerais que expressam necessidades, exigências, metas, repressões e novas concepções. Dentro dêsse panorama, a nova ética da administração pública e os valôres a ela incorporados, quando suficientemente fortes e difundidos entre o povo, contribuem para que o desenvolvimento tenha capacidade para perdurar e fortale cer-se. O que distingue a ética da administração pública, num país em desenvolvimento, é a confiança depositada na capacidade da experiência humana para gerar objetivos e métodos mediante 
os quais o desenvolvimento do país crescerá ordenadamente em abundância; dessa experiência nasce a convicção generalizada de que a escassez, as disparidades, ou os desniveis desproporcionados, embora possam provocar uma multiplicação das áreas de mal-entendidos e conflitos, podem também ser sanadas por uma administração competente, sem desnecessários riscos de sofrimento, ressentimento ou despesas. Estamos cônscios da necessidade de maior conhecimento sôbre a adaptabilidade da administração pública ao desenvolvimento nacional; reconhecemos, ao mesmo tempo, porém, que se a administração pública se revelar incapaz de enfrentar um nôvo complexo de problemas com que não está familiarizada, o desenvolvimento nacional tenderá para oscilar de um problema para outro: é que os problemas são inerentes à crescente complexidade e sofisticação do desenvolvimento. Encarada dêste ângulo, a ética da administração pública reclama:

$\left.1^{\circ}\right)$ Reconhecer o mérito peculiar do desenvolvimento nacional e introduzir nova mentalidade nos tipos precursores de ação apropriados às necessidades e fases de desenvolvimento do país.

2:) Converter as aspirações gerais sôbre o desenvolvimento nacional num programa de ação realistico, que inclua objetivos a atingir, metas de trabalho, bem como prazos baseados no caráter e nas tradições do povo, mantendo, apesar disto, um ritmo de reali-
zação.

39) Criar uma estratégia de desenvolvimento, que isole e ressalte aquilo que é aparentemente estratégico, sem se deixar prenprática.

49) Estimular o crescimento de instituições nacionais permanentes, capazes não só de introduzir mas também de manter as reformas e os novos serviços gerados pelo desenvolvimento e que encontram, na prática, fortes e profundamente arraigadas resis-

59) Demonstrar iniciativa contínua e consciente para introduzir inovações nas diretrizes e processos, bem como assumir pelo menos parte da responsabilidade pela sua aplicação, desde sua

69) Saber distinguir entre ação e inação; isto é, entre alternativas de ação, suas conseqüências imediatas e a longo prazo, e os de ceder terreno.

7०) Criar

os quais forneceramentos adequados para dominar a desordem, nova ordem da experiên matéria-prima capaz de fazer surgir uma

8:) Descobrir a perspectiva corres consagrados do homem. identificar seus elementos unificadores e obter formulações dinâ- 
micas, corretas, baseadas na convicção de que assim como a administração pública pode adaptar-se às novas exigências do desenvolvimento nacional, do mesmo modo poderá readaptar-se.

$\left.9^{\circ}\right)$ Esforçar-se por encontrar outras soluções que não as precedentes, de modo a que uma situação única receba uma solução única.

10\%) Empreender continua reavaliação e reexame dos processos da administração pública, a fim de verificar se êles correspondem às exigências da época; conseqüentemente, rever e aperfeiçoar tais processos, tendo em mente que a perfeição se não de todo inatingivel, está sempre distante, e que cada geração tem uma contribuição a oferecer. 